Article

\title{
Kinetic Analysis of Stabilizing C-Phycocyanin in the Spirulina platensis Extracts from Ultrasonic Process Associated with Effects of Light and Temperature
}

\author{
Woon Yong Choi ${ }^{1}$ and Hyeon Yong Lee ${ }^{2, *}$ \\ 1 Department of Medical Biomaterials Engineering, Kangwon National University, Chuncheon 200701, Korea; \\ cwy1012@hanmail.net \\ 2 Department of Food Science and Engineering, Seowon University, Cheongju 361742, Korea \\ * Correspondence: hyeonl@seowon.ac.kr; Tel.: +82-432998471
}

Received: 21 August 2018; Accepted: 11 September 2018; Published: 14 September 2018

\begin{abstract}
A kinetic model was developed to reflect the stability of C-Phycocyanin (C-PC) from ultrasonic extraction process under different storage conditions. The decrease of C-PC contents was most accelerated at a high temperature of $40^{\circ} \mathrm{C}$ along with light illumination, resulting in ca. $60 \%$ drop of an initial concentration for two months of storage. However, ca. $93 \%$ of the initial contents remained at $4{ }^{\circ} \mathrm{C}$ without light, which would be a most favorable condition for long-term storage. It was first shown that the decrease of the residual concentrations followed second-order kinetics under light illumination. However, without light, the decrease of the C-PC contents showed first order reaction kinetics, which implies initial C-PC concentrations are important. On the contrary, initial storage temperature seemed to be more influential under light illumination. It was also first revealed that the rate of degrading the C-PC was faster with light than without light even at the same temperature, having $0.0108(1 / \mathrm{h})$ and $0.0138(1 / \mathrm{h})$ of rate constants of first order (no light) and second order kinetics (with light) at $40{ }^{\circ} \mathrm{C}$, respectively. Moreover, the cleavage of C-PC was also found to follow the Arrhenius relationship. Therefore, this work could provide desirable storage conditions of C-PC from non-thermal ultrasonic process for long-term storage.
\end{abstract}

Keywords: Spirulina platensis; C-phycocyanin; ultrasonic extraction; kinetics analysis

\section{Introduction}

C-phycocyan (C-PC) is a well-known bioactive substance existing in Spirulina sp. and other cyanobacteria and red algae [1,2]. Some of these, especially Spirulina sp., contain fairly high amounts of C-PC in the ranges of 10-20\% [1,3] in nature; C-PC has been used as a functional blue dye since it has been known to have many biological activities such as antioxidant activities, immune-modulatory activities and anticancer activities, etc. [4,5]. One of the main light harvesting pigments in Spirulina sp. is known as phycobiliproteins that is structured by phycobilisomes, and phycobilisomes are composed of three types of biliproteins such as C-phycocyanin (C-PC), phycoerythrin (PE), and allophycocyanin (APC) $[1,6]$. However, C-PC is also known to be extremely sensitive to heat and $\mathrm{pH}[7,8]$, and its extraction yields were seriously affected by temperature as well as purity [9]. This sensitivity increases its production cost and also decreases its biological functions during production and storage. Therefore, many processes have been studied to obtain high amounts of intact forms of phycocyanins from Spirulina by employing various extraction processes such as freezing and thawing, enzyme digestion, and extraction with various solvents at relatively low temperatures [9,10]. However, in general, low temperature extraction process did not have high enough extraction yields from many biomaterials $[11,12]$. Among them, the ultrasonic process has been proved to be very effective in 
extracting heat labile substances from many bioresources, because in a short time, high speed ultrasonic vibration generates many captivation bubbles that can effectively break the cell walls due to shock wave and liquid jets by collapsing the bubbles near the cell walls [13-16]. Therefore, the ultrasonic process has been considered a non-thermal green extraction process that can obtain heat sensitive bioactive substances such as C-PC at low temperatures with relatively high efficiency; however, this process also has the disadvantage of scaling-up the processes up to 5-10 tons so far [17-19]. Besides effective extraction of intact C-PC, many works on the stability of C-PC have also been carried out to mainly find the effects of temperature and $\mathrm{pH}$ in processing Spirulina sp. or for a week of short term storage [20]. Moreover, reports of the effect of the light are few, even though the importance of the exposure to the light should also be considered. Therefore, temperature and light must be accounted for as the most important variables in maintaining C-PC extracted from Spirulina, especially in terms of storage in many food industries. However, there have not been studies on the changes of the concentrations and purity of C-PC for long-term storage experiments, since most results have been from studies carried out for less than a week [20,21]. Moreover, there is no report of considering the combined effects of both temperature and light on the stability of C-PC for a short-term storage condition, even though the effects associated with both major factors could represent the actual storage conditions in the fields. Therefore, in this work, comprehensive kinetic studies on degrading the C-PC in the extract will be investigated by considering simultaneous changes of temperature and light for long-term periods of storage.

\section{Materials and Methods}

\subsection{Preparation of Spirulina Extract and Exposed to Various Storage Conditions}

First, $10 \mathrm{~g}$ of Spirulina platensis powder (Nutrex, Kona, HI, USA) were mixed with $500 \mathrm{~mL}$ of $50 \mathrm{mM}$ sodium phosphate buffer ( $\mathrm{pH}$ 6.8) and extracted by an ultrasonic extractor (AUG-R3-900, ASIA Co., Gyeonggido, Korea) with $40 \mathrm{kHz}$ frequency at $120 \mathrm{~W}$ of input power by an ultrasonic wave generator located at the bottom of the inside of the extraction vessel for $5 \mathrm{~h}$. Temperature of the ultrasonic extractor was maintained as $25^{\circ} \mathrm{C}$ by a cold water cooling double jacket at the outside of the extraction vessel. Then, the extract was stayed for $12 \mathrm{~h}$ for further extraction at $25^{\circ} \mathrm{C}$. After that, the supernatant was collected by a centrifuge (Combi-514R; HANIL, Daejeon, Korea) at $2800 \times g$ for $30 \mathrm{~min}$. Then, the supernatant was further mixed with hexane $(1: 1, v / v)$ and shaken by a vortex mixer (KMC-1300V; VISION, Daejeon, Korea) for $10 \mathrm{~min}$. Then, the water fraction was collected after staying at $4{ }^{\circ} \mathrm{C}$ for $24 \mathrm{~h}$. For long term storage experiments, the water fraction as an ultrasonic extract (UE) was treated under the following conditions: $200 \mathrm{~mL}$ of the UE was put into a $500 \mathrm{~mL}$ glass jars and stored in a temperature and light controlled incubator equipped with a $20 \mathrm{~W}$ white fluorescent lamp for visible light. For dark experiments, the jar was completely covered with aluminum foil, and the temperature of the incubator was set at 4,25 and $40{ }^{\circ} \mathrm{C}$. Then, $10 \mathrm{~mL}$ of the samples exposed to different storage conditions was collected from the jars every week for two months, and the residual content of C-PC in each sample was measured.

\subsection{Measurement of the C-PC Contents in the Extracts}

The residual concentration of the C-PC in each sample was estimated using high-performance liquid chromatography (HPLC, Dionex 3000, Dionex Co., Sunnyvale, CA, USA) with a $\mathrm{C}_{5}$ column (BIO Widepore, $250 \times 4.6 \mathrm{~mm}, 5 \mu \mathrm{m}$, Sigma, St. Louis, MO, USA) under the following conditions: the injection volume was $20 \mu \mathrm{L}$ and the mobile phase was $20 \%(v / v)$ acetonitrile mixed with $0.1 \%(v / v)$ trifluoroacetic acid at $25{ }^{\circ} \mathrm{C}$ and a $1.0 \mathrm{~mL} / \mathrm{min}$ flow rate under isocratic conditions for $45 \mathrm{~min}$. The absorbance was measured with a UV detector at 580 and $640 \mathrm{~nm}$ and compared to the peaks of a standard C-PC (Sigma, St. Louis, MO, USA) [22,23]. 


\subsection{Kinetic Analysis of Degrading the C-PC during the Storage}

To find a proper kinetic model of breaking down the C-PC under various storage conditions, the first and second order reaction kinetic models were employed because these models have most widely been applied to analyze the dissolution mechanisms within inhomogeneous liquid-solid systems [24,25]:

First-order equation:

$$
\log \left(C_{s}-C_{t}\right)=\log C_{s}-\left(\frac{k_{1}}{2.303}\right) \times t
$$

Second-order equation:

$$
\frac{t}{C_{t}}=\frac{1}{k_{2} C_{s}^{2}}+\left(\frac{1}{C_{s}}\right) \times t
$$

where, $C_{s}$ represents the concentration of initial C-PC in the extract at $t=0$ and $C_{t}$ is the residual concentration at an arbitrary time $t$ (day), and $k_{1}$ and $k_{2}$ represent first-order and second-order rate constants, respectively. To quantitatively understand the effect of temperature on the stability of C-PC, the decrease of residual concentration of C-PC in the extracts was assumed to follow Arrhenius model as follows [24,25]:

$$
k=A \exp \left(-\frac{E}{R T}\right)
$$

where, $k$ is the rate constant observed at three different storage temperatures, $A$ is Arrhenius constant, $R$ is gas constant $\left(0.00814 \mathrm{~kJ} / \mathrm{mol} /{ }^{\circ} \mathrm{K}\right), T$ is absolute temperature of three different storage conditions $\left({ }^{\circ} \mathrm{K}\right)$ and $\mathrm{E}$ is activation energy $(\mathrm{kJ} / \mathrm{mol})$.

\subsection{Statistical Analysis}

The data are expressed as the mean \pm SD (standard deviation) with at least three duplicates, and significant differences among samples were evaluated by ANOVA (SAS Institute, Cary, NC, USA) $(p<0.05)$.

\section{Results and Discussion}

\subsection{The Changes of C-PC Contents in the Extracts Under Various Storage Conditions}

First, Figure 1 was to compare HPLC chromatograms of the C-PC in the extracts from ultrasonic extraction process treated under two extreme storage conditions such as $4{ }^{\circ} \mathrm{C}$ without light (a) and $40{ }^{\circ} \mathrm{C}$ with light (b) after two month exposure.

As a control, initial concentration of C-PC in the extract obtained from ultrasonic extraction process (UE) in Figure 1c was estimated as $10.5(\mathrm{mg} / \mathrm{mL})$, and the amounts of which were found to be similar to other results from a low temperature ultrasonic process and solvent extraction processes [26]. However, after two month storage, there was significant differences between the C-PC contents in two extracts such as $9.41(\mathrm{mg} / \mathrm{mL})$ of C-PC at $4{ }^{\circ} \mathrm{C}$ with no light and $1.13(\mathrm{mg} / \mathrm{mL})$ of C-PC at $40{ }^{\circ} \mathrm{C}$ with light as shown in Figure 1a,b, respectively. It was confirmed that, in storing the UE extract at $4{ }^{\circ} \mathrm{C}$ without light, less than $10.39 \%$ of initial content of the C-PC was decreased even for two months, which tells that C-PC stored at low temperature was very stable. However, at high temperature of $40{ }^{\circ} \mathrm{C}$ with the illumination of the visible light, more than $89.34 \%$ of the C-PC was destructed after two months storage. Therefore, these results clearly proved that the storage conditions must be absolutely critical for a long-term storage of the C-PC. Moreover, the dissociation of the C-PC was much severely accelerated at high temperature associated with the light, which was first found in this work. 
(a)

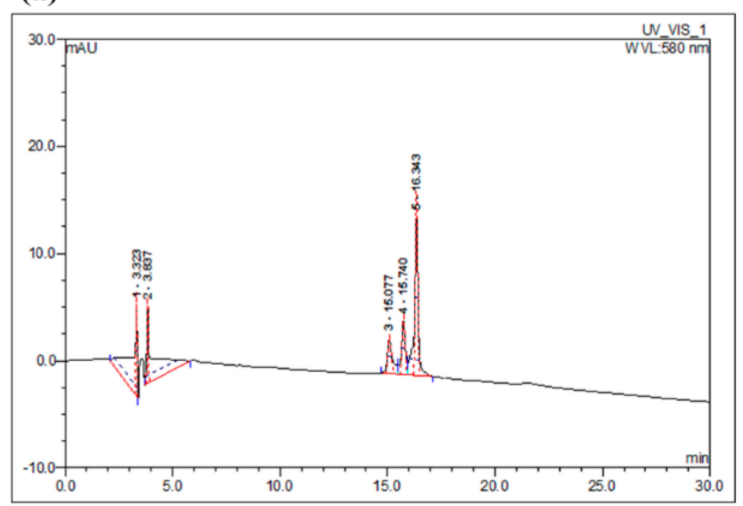

(c)

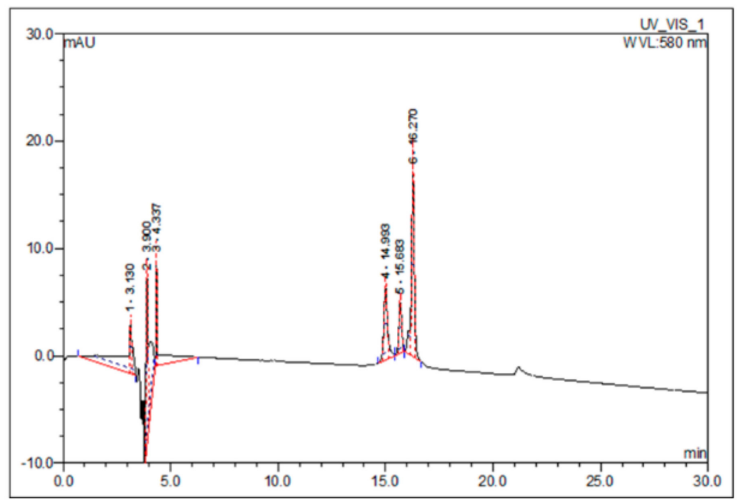

(b)

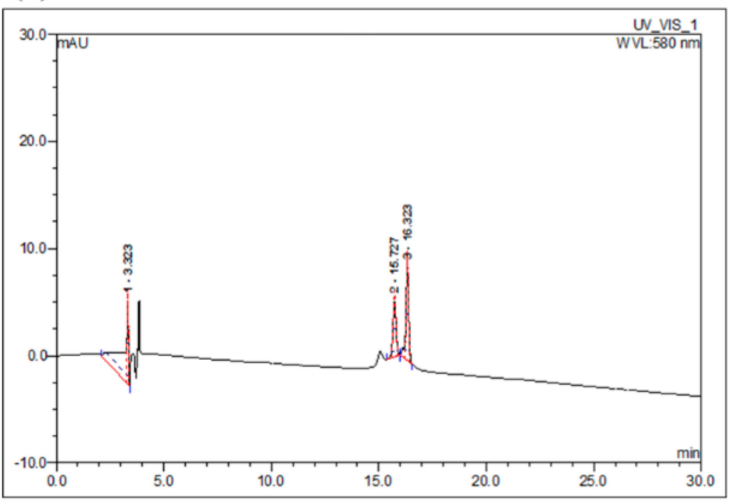

(d)

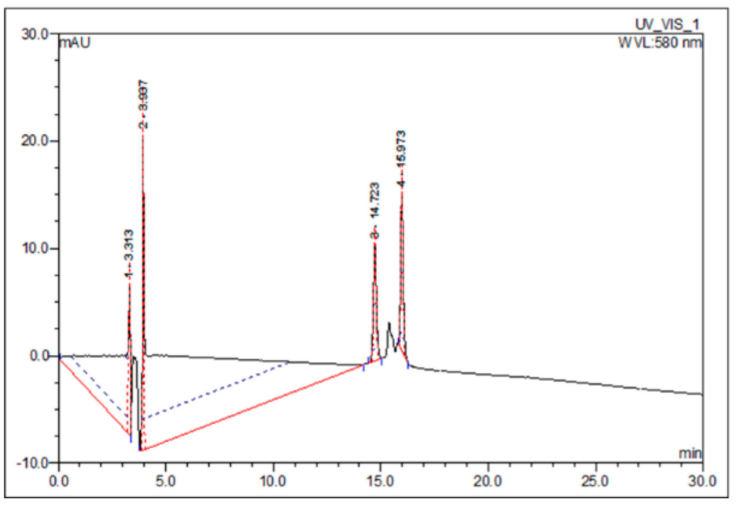

Figure 1. High-performance liquid chromatography (HPLC) chromatograms of C-phycocyanin (C-PC) in the Spirulina platensis extract treated under the conditions stored at $4{ }^{\circ} \mathrm{C}$ with no light (a) and at $40{ }^{\circ} \mathrm{C}$ with light (b) compared with the initial C-PC in the extract as a control (c) and a standard C-PC (d).

Therefore, Figures 2 and 3 were to more comprehensively illustrate the effects of storage temperatures on the breakage of C-PC in the extract by being associated with the effect of the light for two month of long-term storage experiment.

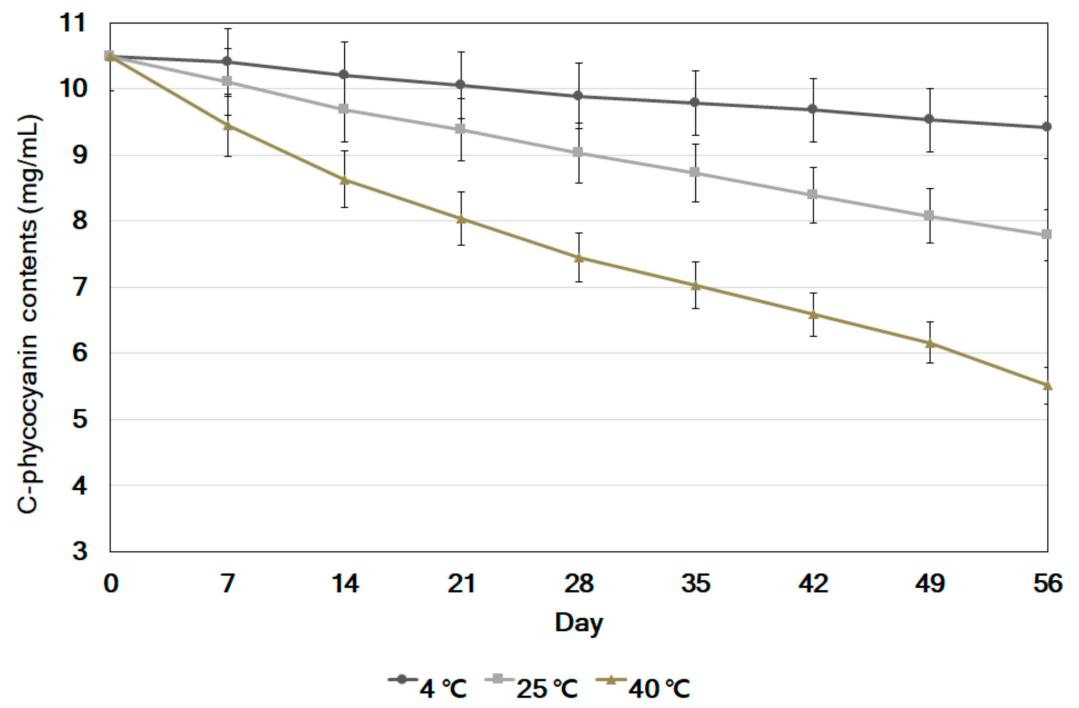

Figure 2. The residual concentration of C-PC in the Spirulina platensis extract at three different temperatures with no light for two months of storage. 


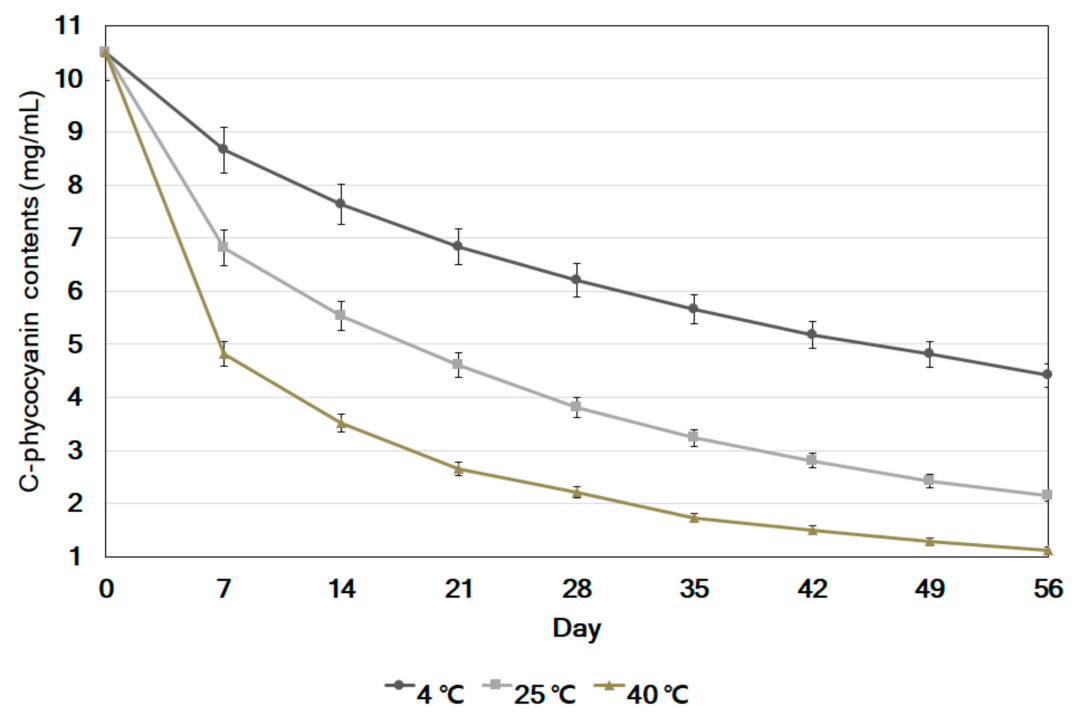

Figure 3. The residual concentration of C-PC in the Spirulina platensis extract at three different temperatures with light for two months of storage.

First, Figure 2 was to compare the decrease of C-PC at three different storage temperatures for two months storage without light. At $4{ }^{\circ} \mathrm{C}$ storage, only ca. $10.39 \%$ drop of C-PC contents in the extract was observed after two months of storage, compared to the initial content at the first day of storage, while $25.81 \%$ of initial concentration was decreased at $25{ }^{\circ} \mathrm{C}$ and ca. $47.53 \%$ at $40{ }^{\circ} \mathrm{C}$ even with no light. These results clearly indicated that the stability of C-PC was greatly decreased at higher temperature and it should be stored at below room temperature at least. Similar results of significant destruction of the C-PC at over $40^{\circ} \mathrm{C}$ of high temperature were reported elsewhere [20,21]; however, there was no report on the effect of temperature for long-term storage, such as more than two months, in this work. Therefore, this result would be first realistic data of representing the stability of C-PC in many experiments. The results of Figures 2 and 3 showed the changes of the amounts of C-PC in the UE extract at three different storage temperatures with light for two months. The patterns of decreasing the contents of C-PC were different from those without light even at same temperature. The final residual concentrations of C-PC in the extract were also much lower being exposed to light than the cases without light as shown in Figure 2: $4.42(\mathrm{mg} / \mathrm{mL})$ with light vs. $9.41(\mathrm{mg} / \mathrm{mL})$ without light at $4{ }^{\circ} \mathrm{C}, 2.15(\mathrm{mg} / \mathrm{mL})$ vs. $7.79(\mathrm{mg} / \mathrm{mL})$ at $25^{\circ} \mathrm{C}$ and $1.13(\mathrm{mg} / \mathrm{mL})$ vs. $5.51(\mathrm{mg} / \mathrm{mL})$ at $40{ }^{\circ} \mathrm{C}$, respectively. It was clearly and first shown that the exposure of light to C-PC significantly accelerates the decrease of the concentrations of C-PC in the extract, and implied that the stability of C-PC should be more greatly affected by simultaneous exposure at high temperature and light for a relatively long period of storage, the conditions of which might reflect actual storage in many industrial fields [27,28].

\subsection{Kinetic Analysis of the Decrease of C-PC with Light and without Light Stored at Various Temperatures}

In considering the decreasing patterns of C-PC in Figures 2 and 3, the results of fitting the data in Figures 2 and 3 to Equations (1) and (2) proved that the changes of residual C-PC concentrations in the extract without light followed first-order reaction kinetics, showing clear straight lines in employing Equation (1) for all three different storage temperatures (Figure 4a) but not well fit to Equation (2) (Figure 4b). On the contrary, as shown in Figure 5, the decrease of C-PC contents in the extracts under light illumination clearly followed second-order kinetic at all of three storage temperatures (Figure 5b), showing continuous drop of C-PC contents until 14 days of storage and slowly decreased after that, especially a great decrease at $40^{\circ} \mathrm{C}$ of high temperature rather than at $4{ }^{\circ} \mathrm{C}$. 

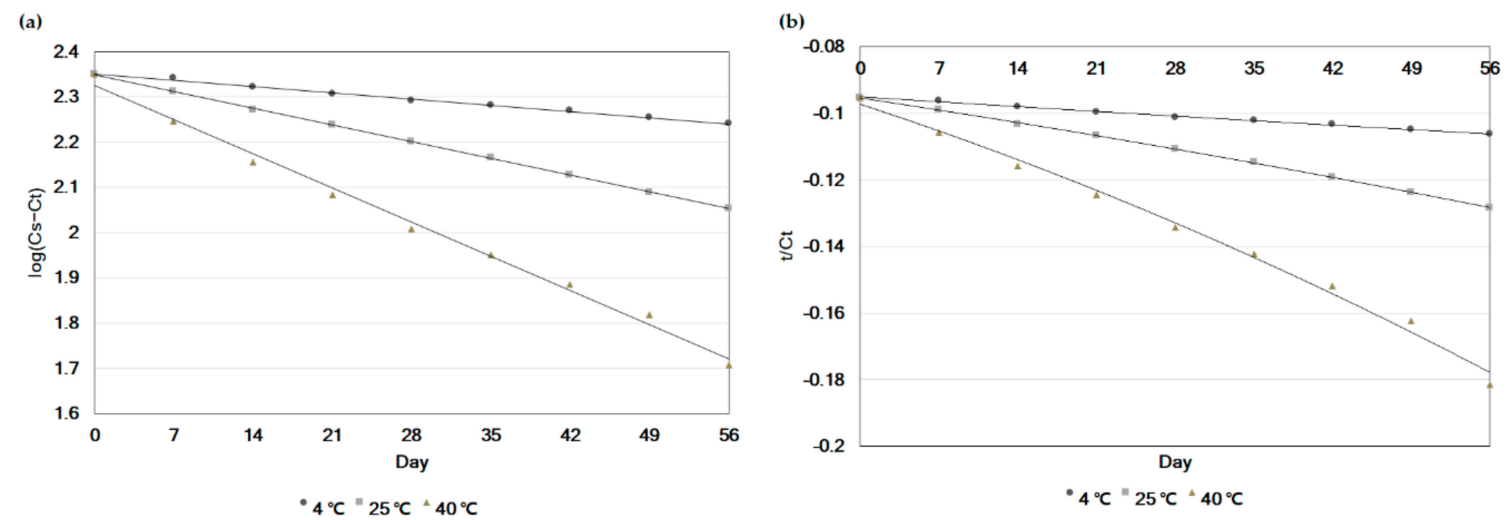

Figure 4. Results of first (a) and second order (b) plots of the decrease of C-PC contents in the extract at three different storage temperatures of $4{ }^{\circ} \mathrm{C}, 25^{\circ} \mathrm{C}$ and $40^{\circ} \mathrm{C}$ without light in Figure 2.

(a)

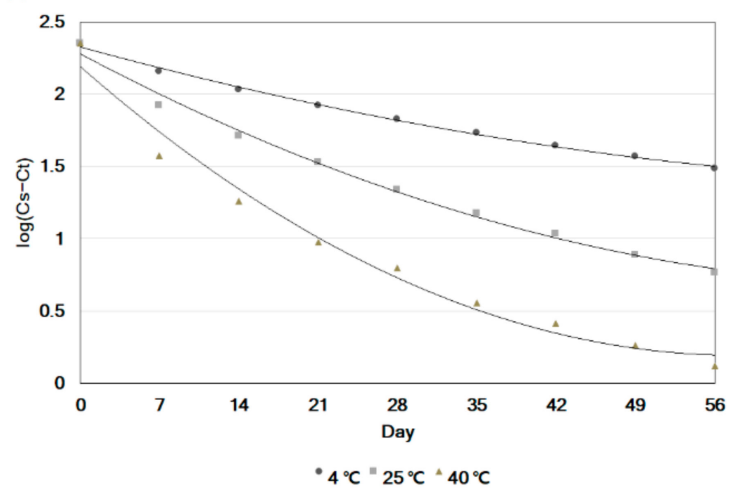

(b)

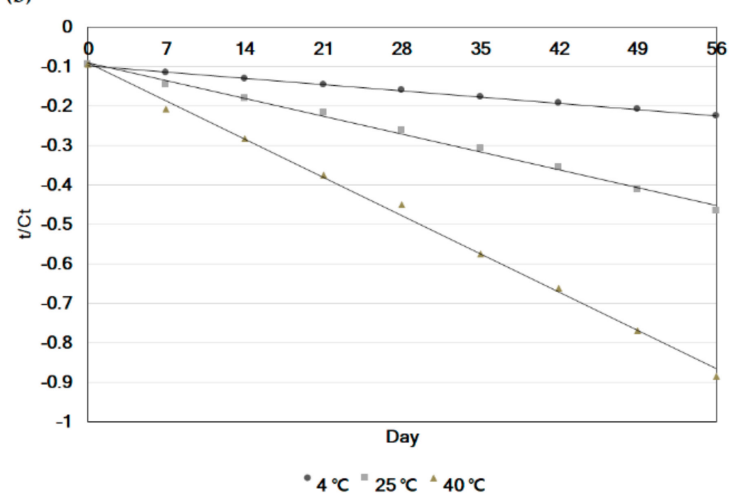

Figure 5. Results of first (a) and second order (b) plots of the decrease of C-PC contents in the extract at three different storage temperatures of $4{ }^{\circ} \mathrm{C}, 25^{\circ} \mathrm{C}$ and $40{ }^{\circ} \mathrm{C}$ with light in Figure 3 .

To confirm the above approximate analysis of two different data sets in Figures 4 and 5, Table 1 shows the results of the estimating rate constants of kinetic analysis by fitting the data in Figures 2 and 3 to the Equations (1) and (2) along with linear regression coefficients $\left(\mathrm{R}^{2}\right)$, which correspond to the results in Figures $4 \mathrm{a}$ and $5 \mathrm{~b}$.

Table 1. The results of estimating first and second order rate constants of decreasing the C-phycocyan (C-PC) contents exposed to light and no light at three different storage temperatures.

\begin{tabular}{ccccc}
\hline Storage condition & Temperature $\left({ }^{\circ} \mathbf{C}\right)$ & \multicolumn{2}{c}{ Rate Constant (1/day) } & $\mathbf{R}^{\mathbf{2}}$ \\
\hline \multirow{3}{*}{ Dark } & 4 & $k_{1(4)}{ }^{*}$ & 0.0020 & 0.9957 \\
& 25 & $k_{1(25)}{ }^{*}$ & 0.0053 & 0.9997 \\
& 40 & $k_{1(40)}{ }^{*}$ & 0.0108 & 0.9932 \\
\hline \multirow{2}{*}{ Light } & 4 & $k_{2(4)}{ }^{* *}$ & 0.0023 & 0.9990 \\
& 25 & $k_{2(25)}^{* *}$ & 0.0065 & 0.9951 \\
& 40 & $k_{2(40)}{ }^{* *}$ & 0.0138 & 0.9970 \\
\hline
\end{tabular}

* The first order rate constant of fitting the data in Figure 4a to Equation (1); ${ }^{* *}$ The second order rate constant of fitting the data in Figure $5 b$ to Equation (2).

All of the data in Figures $4 a$ and $5 b$ were well fitted to Equations (1) and (2), respectively, having fairly good regression coefficients of the ranges of 0.9932 to 0.9997 for all the cases. Rate constant of Equation (1) as first-order kinetic was estimated as 0.0020 (1/day) in Figure $4 \mathrm{a}$ at $4{ }^{\circ} \mathrm{C}$ of storage temperatures and $0.0108(1 /$ day $)$ at $40{ }^{\circ} \mathrm{C}$, respectively. Compared to the rate constants of first order kinetics, the rate constants of second order kinetics (the cases exposed with light) were higher than the cases of no light at all three storage temperatures; 0.0020 vs. 0.0023 (1/day) at $4{ }^{\circ} \mathrm{C}, 0.0053$ vs. 0.0065 
( 1 /day) at $25^{\circ} \mathrm{C}$ and 0.0108 vs. 0.0138 at $40{ }^{\circ} \mathrm{C}$, respectively, which can also confirm the hypothesis that the rate of decreasing and/or breaking intact C-PC was faster than the case of no light at any range of temperature. Interestingly, in other work, the cleavage of the C-PC by methanolysis was also found to be first-order kinetics with $33(1 / \mathrm{h})$ and $0.29(1 / \mathrm{h})$ of breaking $\alpha$ and $\beta$ subunits of C-PC [29], implying that $\alpha$ subunit was more easily detached out of intact C-PC compared to $\beta$ subunit. However, these rate constants seemed to be different from this work because the cleavage model in this work was only considered by a simple two steps of breaking down $\alpha$ and $\beta$ subunit by adding methanol, not naturally decreased by the effects of temperature and light, which was very different from our experimental conditions and purpose. Nevertheless, some of those results could also give an insight of breaking the structure of C-PC intentionally or naturally. It was also confirmed that both cases of our results and the other work revealed that the pattern of breaking the C-PC would follow mostly first-order kinetics, even though under the condition of simultaneous exposure of high temperature and light, the cleavage of C-PC followed second-order kinetics. Therefore, results of this work first found that the decrease of $\mathrm{C}-\mathrm{PC}$ in the extract showed first-order kinetics in storing with no light and second-order kinetic with light, implying that the residual contents of the C-PC were continuously decreased until the end of the storage under no light condition, while the amounts of C-PC were substantially dropped at the first period of storage with light and slowly decreased at latter periods of storage, compared to the cases with no light even at the same temperatures. In particular, it can be expected that the stability of C-PC should be more affected by the initial storage temperature in the case of being exposed to light. Besides the kinetic analysis of decreasing C-PC contents in the extract, it can also be expected that the stability of C-PC should be closely related to temperature, since temperature was found to be a most important factor in long term storage. To understand this relationship, the Arrhenius model in the form of Equation (3) in Materials and Methods, was employed, as shown in Figure 6.

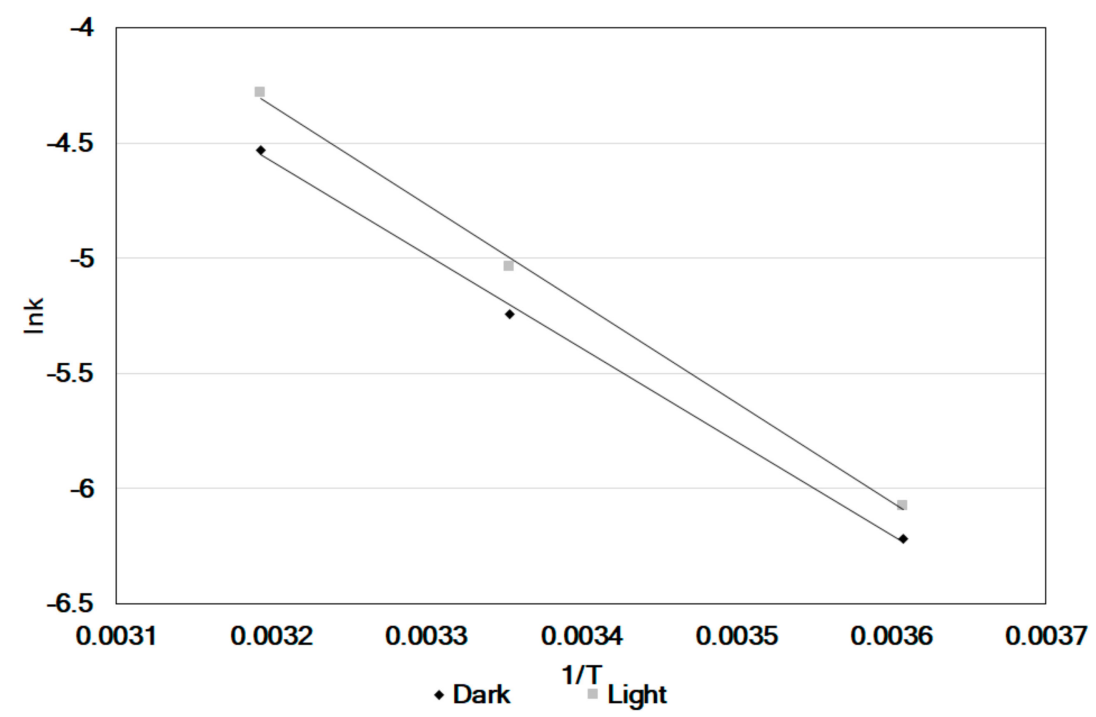

Figure 6. Arrhenius plot of the rate constants of decreasing C-PC contents at $4{ }^{\circ} \mathrm{C}, 25^{\circ} \mathrm{C}$ and $40{ }^{\circ} \mathrm{C}$ with light and no light.

As a result of fitting the rate constants in Table 1 to Equation (3), two activation energy values were calculated as $4045.02(\mathrm{~kJ} / \mathrm{mol})$ and $4298.93(\mathrm{~kJ} / \mathrm{mol})$ for the cases of no light and with light, respectively, along with 0.9986 and 0.9984 of regression coefficient, showing that the decrease C-PC contents in the extracts was considered to fit well with the Arrhenius relationship, too. In general, the activation energy of breaking the C-PC was found to be higher for the case of exposure to light than that of no light, which corresponded to the results that the decrease of residual contents of C-PC followed second-order kinetics, as shown in Table 1 . Therefore, these results could provide useful information in the industrial fields of managing the C-PC, where long term storage would be inevitable. 


\section{Conclusions}

This work first showed simultaneous effects of temperature and light on the stability of C-PC in the extracts from an ultrasonic extraction process by conducting the experiments that could reflect the actual industrial environment of storing and processing C-PC from Spirulina sp. More accelerated destruction of the C-PC was observed at high temperatures with the light, than in the case with no light, even at the same temperature. Kinetic analysis of the residual C-PC contents in the extracts also confirmed a hypothesis first proposed in this work by showing high values of second-order rate constants of decreasing C-PC contents with the light, compared to low values of first-order rate constants for the case of no light at all of the experimental temperature during the storage. The residual amounts of C-PC in the extract continuously decreased until the end of the two months storage as a function of storage temperature under the condition of no light, which strongly implied that initial concentration of C-PC must be more important for long term storage with no light. These results support the advantages of employing the ultrasonic extraction process that can yield more amounts of intact C-PC in the extract from S. platensis than other processes. However, with continuous exposure to light, the contents of C-PC significantly dropped, first at two weeks and then slowly decreased after that, which meant that the initial storage temperature should be more important than the initial concentration, even at the same temperature under the condition of being exposed to light. The effect of temperature on the stability of C-PC was also first found to follow Arrhenius model, showing a higher activation energy of breaking the structure of the C-PC for the case with light, as compared to the case of no light. Therefore, we conclude that non-thermal ultrasonic extraction could help to increase the stability of C-PC in the extract by maintaining relatively low environmental temperatures without light.

Author Contributions: W.Y.C. and H.Y.L. carried out the studies of experiments and drafted the manuscript. All authors read and approved the final manuscript.

Funding: This research received no external funding.

Conflicts of Interest: The authors declare no conflict of interest.

\section{References}

1. Bennett, A.; Bogorad, L. Complementary chromatic adaptation in a filamentous blue-green alga. J. Cell Biol. 1973, 58, 419-435. [CrossRef] [PubMed]

2. Li, B.; Gao, M.H.; Zhang, X.C.; Chu, X.M. Molecular immune mechanism of C-phycocyanin from Spirulina platensis induces apoptosis in HeLa cells in vitro. Biotechnol. Appl. Biochem. 2006, 43, 155-164. [CrossRef] [PubMed]

3. Khan, Z.; Bhadouria, P.; Bisen, P.S. Nutritional and therapeutic potential of Spirulina. Curr. Pharm. Biotechnol. 2005, 6, 373-379. [CrossRef] [PubMed]

4. Romay, C.; Gonzalez, R.; Ledon, N.; Remirez, D.; Rimbau, V. C-Phycocyanin: A biliprotein with antioxidant, anti-Inflammatory and neuroprotective effects. Curr. Protein Pept. Sci. 2003, 4, 207-216. [CrossRef] [PubMed]

5. Lee, J.C.; Hou, M.F.; Huang, H.W.; Chang, F.R.; Yeh, C.C.; Tang, J.Y.; Chang, H.W. Marine algal natural products with anti-oxidative, anti-inflammatory, and anti-cancer properties. Cancer Cell Int. 2013, 13, 55-61. [CrossRef] [PubMed]

6. Cantt, E. Phycobilisomes. Ann. Rev. Plant Physoiol. 1981, 32, 327-347. [CrossRef]

7. Siegelman, H.W.; Kycia, J.H. Handbook of Phycological Methods: Physiological and Biological Methods; Cambridge University Press: Cambridge, UK, 1978; pp. 72-78. ISBN 9780521279420.

8. Abalde, J.; Betancourt, L.; Torres, E.; Cid, A.; Barwell, G. Purification and characterization of phyocyanin from the marine cyanobacterium Synechococcus sp. IO9201. Plant Sci. 1998, 136, 109-120. [CrossRef]

9. Sarada, R.; Pillai, M.G.; Ravishankar, G.A. Phycocyanin from Spirulina sp.: Influence of processing of biomass on phycocyanin yield, analysis of efficacy of extraction methods and stability studies on phycocyanin. Process Biochem. 1999, 34, 795-801. [CrossRef]

10. Moraes, C.C.; Sala, L.; Cerveira, G.P.; Kalil, S.J. C-phycocyanin extraction from Spirulina platensis wet biomass. Braz. J. Chem. Eng. 2011, 28, 45-49. [CrossRef] 
11. Kim, W.I.; Jeong, K.W.; Lee, S.B.; Hong, I.K.; Park, K.A. Ultrasound Energy Effect on Solvent Extraction of Amaranth Seed Oil. J. Korean Ind. Eng. Chem. 2001, 12, 307-311.

12. Martínez, M.L.; Bordón, M.G.; Lallana, R.L.; Ribotta, P.D.; Maestri, D.M. Optimization of Sesame Oil Extraction by Screw-Pressing at Low Temperature. Food Bioprocess Technol. 2017, 10, 1113-1121. [CrossRef]

13. Yamada, T.; Sakaguchi, K. Comparative studies on Chlorella cell walls: Induction of protoplast formation. Arch. Microbiol. 1982, 132, 10-13. [CrossRef]

14. Zheng, H.; Yin, J.; Gao, Z.; Huang, H.; Ji, X.; Dou, C. Disruption of Chlorella vulgaris Cells for the release of biodiesel-producing lipids: A Comparison of grinding, ultrasonication, bead milling, enzymatic lysis, and microwaves. Appl. Biochem. Biotechnol. 2011, 164, 1215-1224. [CrossRef] [PubMed]

15. Wang, M.; Yuan, W. Microalgal cell disruption in a high-power ultrasonic flow system. Bioresour. Technol. 2015, 193, 171-177. [CrossRef] [PubMed]

16. Altemimi, A.; Choudhary, R.; Watson, D.G.; Lightfoot, D.A. Effects of ultrasonic treatments on the polyphenol and antioxidant content of spinach extracts. Ultrason. Sonochem. 2015, 24, 247-255. [CrossRef] [PubMed]

17. Oh, S.H.; Ahn, J.H.; Kang, D.H.; Lee, H.Y. The effect of ultrasonificated extracts of Spirulina maxima on the Anticancer activity. Mar. Biotechnol. 2011, 13, 205-214. [CrossRef] [PubMed]

18. Dranca, F; Oroian, M. Optimization of ultrasound-assisted extraction of total monomeric anthocyanin (TMA) and total phenolic content (TPC) from eggplant (Solanum melongena L.) peel. Ultrason. Sonochem. 2016, 31, 637-646. [CrossRef] [PubMed]

19. Altemimi, A.; Lightfoot, D.A.; Kinsel, M.; Watson, D.G. Employing response surface methodology for the optimization of ultrasound assisted extraction of lutein and $\beta$-carotene from spinach. Molecules 2015, 20, 6611-6625. [CrossRef] [PubMed]

20. Chaiklahan, R.; Chirasuwan, N.; Bunnag, B. Stability of phycocyanin extracted from Spirulina sp.: Influence of temperature, $\mathrm{pH}$ and preservatives. Process Biochem. 2012, 47, 659-664. [CrossRef]

21. Martelli, G.; Folli, C.; Visai, L.; Daglia, M.; Ferrari, D. Thermal stability improvement of blue colorant C-Phycocyanin from Spirulina platensis for food industry applications. Process Biochem. 2014, 49, 154-159. [CrossRef]

22. Boussiba, S.; Richmond, A.E. Isolation and characterization of phycocyanins from the blue-Green alga Spirulina platensis. Arch. Microbiol. 1979, 120, 155-159. [CrossRef]

23. Kumar, D.; Dhar, D.W.; Pabbi, S.; Kumar, N.; Walia, S. Extraction and purification of C-phycocyanin from Spirulina platensis (CCC540). Indian J. Plant Physiol. 2014, 19, 184-188. [CrossRef] [PubMed]

24. Francine, S.A.; Jorge, A.V.C.; Susana, J.K. Thermal degradation kinetics of the phycocyanin from Spirulina platensis. Biochem. Eng. J. 2008, 41, 43-47. [CrossRef]

25. Cho, S.C.; Choi, W.Y.; Oh, S.H.; Lee, C.G.; Seo, Y.C.; Kim, J.S.; Song, C.H.; Kim, G.V.; Lee, S.Y.; Kang, D.H.; et al. Enhancement of Lipid Extraction from Marine Microalga, Scenedesmus Associated with High-Pressure Homogenization Process. J. Biomed. Biotechnol. 2012, 2012, 359432. [CrossRef] [PubMed]

26. Choi, W.Y.; Lee, H.Y. Effect of Ultrasonic Extraction on Production and Structural Changes of C-Phycocyanin from Marine Spirulina maxima. Int. J. Mol. Sci. 2018, 19, 220. [CrossRef] [PubMed]

27. Walter, A.; Carvalho, J.C.; Soccol, V.T.; Faria, A.B.B.; Ghiggi, V.; Soccol, C.R. Study of phycocyanin production from Spirulina platensis under different light spectra. Braz. Arch. Biol. Technol. 2011, 54, 675-682. [CrossRef]

28. Colla, L.M.; Bertol, C.D.; Ferreira, D.J.; Bavaresco, J.; Costa, J.A.V.; Bertolin, T.E. Thermal and photo-stability of the antioxidant potential of Spirulina platensis powder. Braz. J. Biol. 2016, 77, 332-339. [CrossRef] [PubMed]

29. Chandrakant, R.M.; Maria, C.R.S.; Knud, V.C.; Xavier, F.; Lars, P.C. Kinetics of Phycocyanobilin Cleavage from C-Phycocyanin by Methanolysis. Comput. Aided Chem. Eng. 2016, 38, 61-66. [CrossRef]

(C) 2018 by the authors. Licensee MDPI, Basel, Switzerland. This article is an open access article distributed under the terms and conditions of the Creative Commons Attribution (CC BY) license (http://creativecommons.org/licenses/by/4.0/). 